\title{
Antioxidant and Antidiabetic Activities of Biologically Synthesized Silver Nanoparticles using Linum usitatissimum Extract
}

\author{
KANMANI R and IRUDAYA IRIN SCLEEVA P \\ Department of Chemistry, Holy Cross College (Autonomous), Affiliated to \\ Bharathidasan University, Tiruchirappalli-2, Tamilnadu, India. \\ *Corresponding author E-mail : kanmanivincy@gmail.com \\ http://dx.doi.org/10.13005/ojc/370531
}

(Received: August 17, 2021; Accepted: September 18, 2021)

\begin{abstract}
This research work is mainly focused to study the anti-oxidant and anti-diabetic activities of biologically synthesis of silver nanoparticles (AgNPs) from the flaxseed extract of Linum usitassimum. Qualitative tests identify the presence of phytochemicals in the flax seed extract and its results showed the presence of tannins, terpenoids, saponins, flavonoids, steroids, cardiac glycosides, anthraquinones, coumarins, xanthoproteins, alkaloids, emodins, and carbohydrate in it. Preliminarily AgNPs formation is confirmed by the UV-spectra and it showed maximum adsorption band at $438 \mathrm{~nm}$. FT-IR spectroscopic studies reveal the Phyto-constituents which are involved in the reduction of silver $\left(\mathrm{Ag}^{+1}\right)$ into silver nanoparticles $\left(\mathrm{Ag}^{0}\right)$. The spherical shapes of AgNPs are observed with crystalline nature are found in the aid of SEM and XRD analysis. Synthesized AgNPs have the maximum percentage of a silver element which is examined by the EDX analysis. The In vitro antioxidant and antidiabetic activities of $L$. usitatissimum mediated AgNPs were analyzed by using the DPPH, alpha-amylase, and alpha glycosides assays respectively. The DPPH result shows that the AgNPs possess $59.01 \%$ of radical scavenging property and the standard ascorbic acid reveals $48.63 \%$ at $100 \mu \mathrm{g} / \mathrm{mL}$ concentration. Similarly in anti-diabetic activity, AgNPs shows the maximum inhibition of $79.84 \%$ in the alpha-amylase assay, and for alpha-glucosidase, AgNPs showed $58.86 \%$ at $100 \mu \mathrm{g} /$ $\mathrm{ml}$ concentration.
\end{abstract}

Keywords: Linum usitassimum, Silver nanoparticles, Anti-oxidant activity, Anti-diabetic activity.

\section{INTRODUCTION}

Nanoscience technology is a multidisciplinary subject and it is widely used in research areas of physics and chemistry. Various physical, chemical, and greener syntheses processes are available in nanoparticle (NPs) production. Chemical and physical methods are more labor-intensive and also possess hazardous than the biological (green method) synthesis. The greener process is non-toxic, reproducible, eco-friendly, one step, easy, and more efficient. In additionally the greener method consumes low energy, it produces harmless and stable products. In the greenway, the plant extract-based nanoparticles synthesize get more attention than the other green methods (fungus, algae, bacteria, etc.). ${ }^{1-4}$

This is an Open Access article licensed under a Creative Commons license: Attribution 4.0 International (CC- BY). Published by Oriental Scientific Publishing Company @ 2018

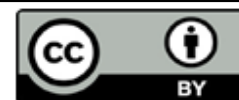


The most viable nanomaterial is silver nanoparticles (AgNPs) which are more commercialized nano-materials and nearly 500 tons of AgNPs were produced per year. Owing to high sensitivity in the detection of biomolecules, medicine, and catalysis silver nanoparticles were recognized as a strong pharmacophore. A wide range of medical applications are revealed by the silver nanoparticles (AgNPs) and are wound healing, dental material fills, bone repairing, anti-diabetics, vaccine adjuvants, bio-imaging, and biosensors. ${ }^{5,6}$ Flax or Linum usitatissimum is commonly known as the linseed which is the flowering plant, and it belongs to the Linaceae family. Traditionally it is used in the treatment of gastrointestinal infections and diarrhea. Flaxseed has macro and micronutrients along with that it has an excess of omega-3 fatty acids and vitamin B6. It has $54 \%$ of omega- 3 fatty acids, $18 \%$ of oleic acid (omega- 9 fatty acids), $6 \%$ of linoleic acid (omega- 6 fatty acids), $9 \%$ of saturated fat, and $5 \%$ of palmitic acid. Diabetes mellitus is an endocrine disorder. Due to insulin resistance and deficiency which results from the high level of sugar in the blood for an extended period which is referred to as diabetes mellitus. This research work mainly aimed to study the In vitro of anti-oxidant and anti-diabetic activities of green synthesized silver nanoparticles mediated from Linum usitatissimum. . $^{7-9}$

\section{MATERIALS AND METHODS}

\section{Plant collection and extraction}

The fresh flax seeds were collected from the Thiruvarur district, Tamilnadu, India. Diseasefree seeds were washed thoroughly with the running water several times. Then again seeds were washed by double distilled water to remove other watersoluble impurities. After that seeds were dried in sunshade then make into a fine powder using the mechanical grinder. $100 \mathrm{~g}$ of seed powder was taken in a $500 \mathrm{~mL}$ dry beaker and to that $300 \mathrm{~mL}$ of ethanol was added. Then heated on the water bath, the final extract is filtered through the Whatman No.41 filter paper. Filtered extract was stored in the brown bottle which is used for further analysis.

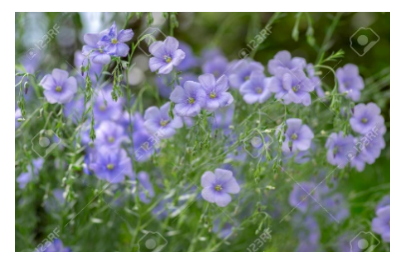

Fig. 1. Images of Linum usitatissimum

\section{Qualitative and Quantitative analysis of Aqueous} Extract of Linum usitatissimum

The various phytochemical tests (qualitative) were performed to establish the profile of the Linum usitatissimum extract. Primary and secondary metabolites presence was tested by the screening tests against the metabolites such as tannins, carbohydrates, terpenoids, phenolics, anthocyanins, and flavonoids, etc., Quantification of these metabolites can be performed by the standard protocols which estimate the total amount of Flavonoids, Tannins, Saponins, Alkaloids, Phenol and Terpenoids in the seed extract. ${ }^{10}$

\section{Synthesis and Characterisation of AgNPs using Linum usitatissimum Extract}

$1 \mathrm{mM}$ concentration of silver nitrate is prepared in a $50 \mathrm{~mL}$ standard flask, and the flask was covered with aluminum foil to prevent photochemical reactions with sunlight. $50 \mathrm{~mL}$ of $1 \mathrm{mM}$ silver nitrate solution was taken in a $300 \mathrm{~mL}$ beaker to this $50 \mathrm{~mL}$ of seed extract is slowly added then kept on a stirrer for 5 hours. After that, the reaction mixture was kept at room temperature for $24 \mathrm{~h}$ to complete the reaction. Then formed nanoparticles were collected by centrifuging at 6000rpm. Collected AgNPs were washed with double distilled water and followed by ethanol several times to remove impurities from that. Subsequently, AgNPs were dried in a hot air oven for 6 to $12 \mathrm{~h}$ to achieve high purity of obtained AgNPS. The formation of any nanoparticles is initially confirmed by the UV-Visible spectral studies. The same AgNPs formation is identified by analyzing 2 $\mathrm{mL}$ of colloidal AgNPs on UV-Visible. A small quantity of dried AgNPs was taken for the FT-IR analysis in the range of $500 \mathrm{~cm}^{-1}$ to $4000 \mathrm{~cm}^{-1}$ to identify the functional groups present in the extract which involves in the AgNPs synthesis. Similarly, the morphology of synthesized AgNPs was analyzed by SEM (1-10nm), Elemental composition by EDX (1-10KeV), and Crystallinity by XRD $\left(10^{\circ}<2 \theta<80^{\circ}\right)$ studies. ${ }^{11,12}$

\section{In vitro antioxidant activity of AgNPs by DPPH method}

The $20,40,60,80$, and $100 \mu \mathrm{g} / \mathrm{mL}$ of AgNPs were taken in the five different test tubes then $1 \mathrm{~mL}$ of ethanol was added and mixed well. To each test tubes, $3 \mathrm{~mL}$ of $0.1 \mathrm{mM}$ DPPH was added and kept in a dark room for 30 minutes. After the reaction time interval, the absorbance of each mixture was recorded at $517 \mathrm{~nm}$ using the spectrophotometer. 
Blank served as without adding NPs. From the below equation the percentage of inhibition of DPPH scavenged is calculated.

DPPH activity $(\%$ inhibition $)=[(A-B) / A] \times 100$

$A$ and $B$ represents the absorbance value for the test samples (NPs added DPPH) and blank sample. The percent inhibition versus concentration curve and $50 \%$ inhibition was determined from the concentration verse inhibition percentage graph. ${ }^{13}$

\section{In vitro antidiabetic activity of AgNPs by Alpha- amylase inhibition assay}

The alpha-amylase inhibitory protocol was given by McCue and Shetty. Five different concentration of AgNPs (20, 40, 60, 80 and $100 \mu \mathrm{g} /$ $\mathrm{mL}$ ) was taken in a test tube and $1 \mathrm{~mL}$ of ethanol added to each tube. To this $250 \mu \mathrm{L}$ of sodium phosphate buffer ( $\mathrm{pH}$ 6.9) containing a-amylase solution $(0.5 \mathrm{mg} / \mathrm{mL})$ is added and incubated for $10 \mathrm{~min}$ at room temperature. Over $250 \mu \mathrm{L}$ of $1 \%$ starch in $0.02 \mathrm{M}$ sodium phosphate buffer $(\mathrm{pH} 6.9)$ was added again incubated for 10 minutes. To that $500 \mu \mathrm{L}$ of dinitrosalicylic acid (DNS) reagent is added slowly and heated on a water bath for $5 \mathrm{~min}$ and their absorbance was measure at 540nm in a spectrophotometer by diluting and cooling the samples. The a-amylase inhibition percentage was calculated by the below equations.

$\%$ Inhibition $=[($ Abs control - Abs sample $) /$ Abs control] $\times 100$

Where Abs control and Abs of the sample represent the absorbance value for the test and blank sample respectively.

\section{In vitro antidiabetic activity of AgNPs by Alpha glucosidase inhibition assay}

The a-glucosidase protocol was initiated by Saccharomyces cerevisiae. Five different concentration of AgNPs (20, 40, 60, 80 and $100 \mu \mathrm{g} /$ $\mathrm{mL}$ ) was taken in a test tube and $1 \mathrm{~mL}$ of ethanol added to each tube. $100 \mu \mathrm{L}$ of a-glucosidase is added to each test tube and incubated for 10 minutes. To that $50 \mu \mathrm{L}$ of $3 \mathrm{mM}$ P-nitro phenyl glucopyranoside was added followed by incubation for $20 \mathrm{~min}$ at $37^{\circ} \mathrm{C}$. Two milliliters of $0.1 \mathrm{M}$ sodium carbonate were added then the absorbance of each mixture is spectroscopically measured at $405 \mathrm{~nm}$ by spectrophotometer. Blank was performed similarly except for the addition of samples. The inhibition percentage of a-glucosidase was calculated by the below equation.

$\%$ Inhibition $=[($ Abs control - Abs aqueous $) / A b s$ control] x 100 .

Where $A$ and $B$ represent the absorbance value for the test and blank sample respectively. ${ }^{14,15}$

\section{RESULTS AND DISCUSSION}

\section{Qualitative results of Linum usitatissimum seed extract}

The results of phytochemical screening of Linum usitatissimum seed extract on different qualitative tests are represented in Table 1 and Fig. 2. The screening results revealed that the seed extract shows the presence of tannins, saponins, flavonoids, steroids, terpenoids, cardiac glycosides, anthraquinones, coumarins, xanthoproteins, alkaloids, emodin, carbohydrates which are responsible for medicinal activities while leucoanthocyanin, phlobatannin, and phenol were absent.

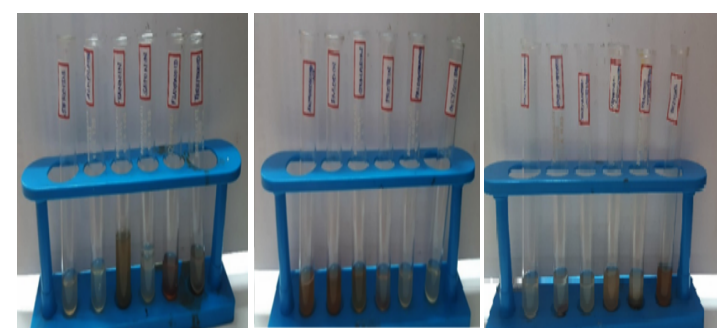

Fig. 2. Images of Phytochemical Screening Results of Linum usitatissimum

Table 1: Qualitative analysis of seed of Linum usitatissimum

\begin{tabular}{cccc}
\hline S.No & Phytocompounds & Observation & Results \\
\hline 1 & Terpenoids & No precipitate & Absent \\
2 & Flavanoid & Yellow color & ++ \\
3 & Saponin & Forth form & +++ \\
4 & Tannin & Brownish green & +++ \\
5 & Alkaloid & Yellow color & +++ \\
6 & Steroids & No precipitate & Absent \\
7 & Glycosides & No precipitate & Absent \\
8 & Phlobatannins & No precipitate & Absent \\
9 & Proteins & White precipitate & ++ \\
10 & Coumarin & Yellow color & +++ \\
11 & Emodin & Red color & +++ \\
12 & Anthraquinone & Red & +++ \\
13 & Carbohydrates & Reddish violet color & +++ \\
14 & Leucoanthocyanin & No precipitate & Absent \\
15 & Cardiac glycosides & Brown ring & ++ \\
16 & Anthocyanin & Bluish violet & +++ \\
17 & Xanthoproteins & Reddish orange precipitate & +++ \\
18 & Phenol & Blue-black & +++ \\
\hline
\end{tabular}


Quantitative results of Linum usitatissimum seed extract

From the quantitative analysis results, the phytoconstituents composition in the Linum usitatissimum seed extract has been reported in different amounts. It reveals that alkaloids $(0.193$ $\mathrm{mg} / \mathrm{g}$ ) are present in higher percentage in the seed extract followed by saponins $(0.089 \mathrm{mg} / \mathrm{g})$, phenols $(0.011 \mathrm{mg} / \mathrm{g})$, tannin $(0.008 \mathrm{mg} / \mathrm{g})$, flavonoids $(0.006$ $\mathrm{mg} / \mathrm{g})$, and terpenoids $(0.003 \mathrm{mg} / \mathrm{g})$ which was given in the Table 2 and Figure 3.

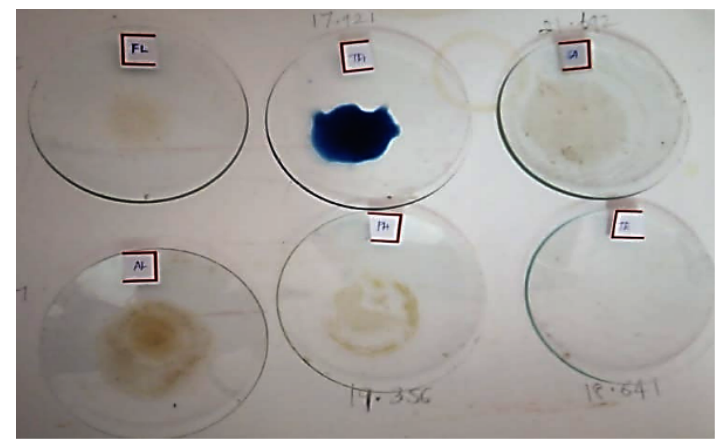

Fig. 3. Quantitative analysis results of Linum usitatissimum seed extract; FL-flavonoid, AL-alkaloids, TR-terpenoids, PH-phenolics, SA-saponins and TA-tannins quantification images

Table 2: Quantitative analysis of Linum usitatissimum seed extract.

\begin{tabular}{lcc}
\hline S.No & Phytochemical Constituents & Samples $(\mathrm{mg} / \mathrm{g})$ \\
\hline 1 & Flavonoids & $0.006 \mathrm{mg} / \mathrm{g}$ \\
2 & Tannin & $0.008 \mathrm{mg} / \mathrm{g}$ \\
3 & Saponins & $0.089 \mathrm{mg} / \mathrm{g}$ \\
4 & Alkaloids & $0.193 \mathrm{mg} / \mathrm{g}$ \\
5 & Phenol & $0.011 \mathrm{mg} / \mathrm{g}$ \\
& Terpenoids & $0.003 \mathrm{mg} / \mathrm{g}$ \\
\hline
\end{tabular}

Spectral characterization of AgNPs using Linum usitatissimum seed extract

The color changes are the main identification step in nanoparticles synthesis. For AgNPs formation after adding ethanol extract the colorless solution of silver nitrate turns into brown and it extended to dark brown. Similarly, the UV-Visible results of synthesized AgNPs showed maximum adsorption of $445 \mathrm{~nm}$ which denotes the formation of silver nanoparticles in the resulted mixture i.e. the plasma resonance was observed in the range of $445 \mathrm{~nm}$ which related AgNPs.

FT-IR spectrum of ethanolic extract of L. usitatissimum, which gives information about the functional groups of phytochemicals present in the raw extract. Observed peaks were shown in the Fig. 5 and their data was given in the Table 3 .

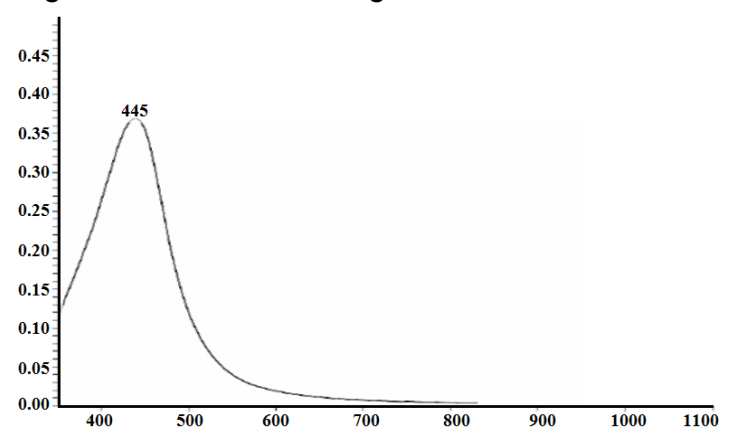

Fig. 4. UV-Vis spectrum of synthesized silver nanoparticles

Table 3: FTIR band values of synthesized silver nanoparticles

\begin{tabular}{ll}
\hline $\begin{array}{l}\text { The observed frequency of } \\
\text { the synthesized AgNPs }\left(\mathrm{cm}^{-1}\right)\end{array}$ & Assignment of functional group \\
\hline $\begin{array}{l}\text { Strong band at } 3331 \\
\text { Strong band } 2358\end{array}$ & $\begin{array}{l}\text { O-H Stretching and H-bonded } \\
\text { C-N in aliphatic amine } \\
\text { Strong band at } 1639\end{array}$ \\
$\begin{array}{l}\text { C-O stretching in aliphatic } \\
\text { ether }\end{array}$ \\
Strong band at 1462 & $\begin{array}{l}\text { C-F stretching in fluoro } \\
\text { compound }\end{array}$ \\
Broadband at 659 & -C=C- in alkenes. \\
A medium band at 599 & $\begin{array}{l}\text { Medium C=C stretching } \\
\text { conjugated alkenes }\end{array}$ \\
Strong band at 557 & C-Br stretching in Halo \\
& compound \\
\hline
\end{tabular}

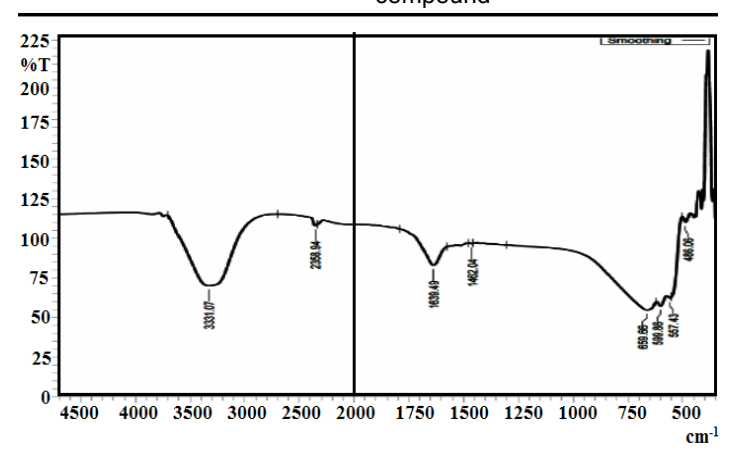

Fig. 5. FT-IR spectrum of synthesized silver nanoparticles

The SEM images of synthesized AgNPs were given in the Fig. 6 . The average size of obtained particles was found to be $82.34 \mathrm{~nm}$, and it was in needle shapes with well dispersed and almost uniform in nature. Mostly in the greener method, spherical shapes of NPs were observed but for the first time, needle shapes of AgNPs were reported in the green method.

Through Energy dispersive X-ray (EDX) analysis the elemental composition of AgNPs was studied and their signals (from Table 4 and Fig. 7) confirms the presence of elemental silver in it. In this 
$59 \%$ of silver was present in the formed AgNPS and similarly, it has $25 \%$ of oxygen, $12 \%$ of copper, and $3 \%$ of sulfur.

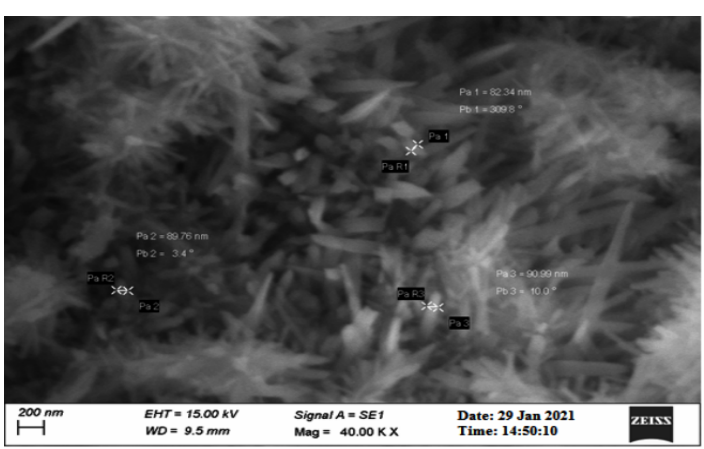

Fig. 6. SEM image for synthesized silver nanoparticles

Table 4: Elemental composition of synthesized AgNPs

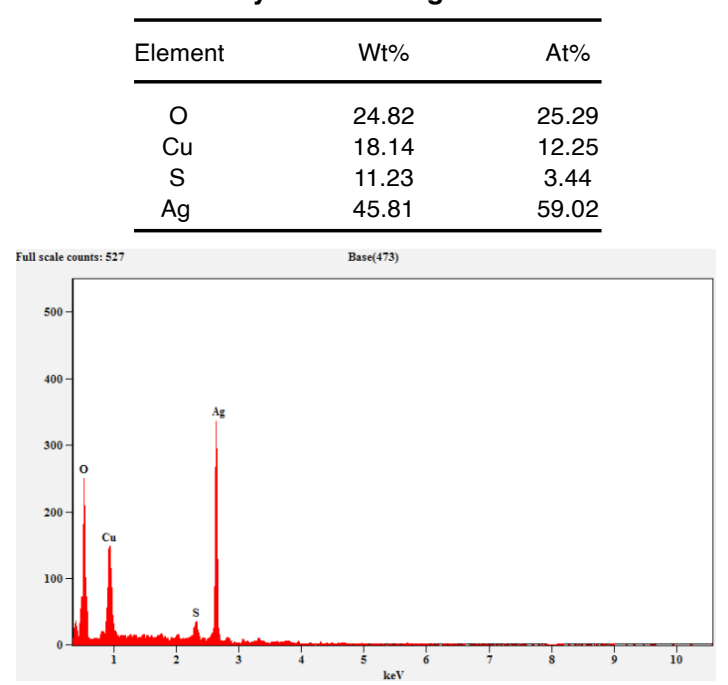

Fig. 7. EDX spectrum of synthesized AgNPs

In X-ray crystallography analysis of AgNPs was studied and its resulted spectra are shown in the Fig. 8. The results exhibit that AgNPs are in crystalline form with the intense diffraction peaks at $2 \theta$ values of $38.35,45.63,67.14$, and 78.28 which are correspond to the plane of (111), (200), (220), and (311) respectively. The observed AgNPs patterns were in face-centered cubic which has a similar pattern of JCPDS, File No. 04-0783. Few unassigned peaks were found in the XRD results which may be from ethanolic extract of $L$. usitatissimum (because of the presence of phytochemicals).

\section{Antioxidant activity of synthesized AgNPs by DPPH assay}

The result depicts that the synthesized AgNPs showed maximum potent antioxidant activities at high concentrations as compared with standard ascorbic acid Table 5. The synthesized silver nanoparticles showed $59.01 \%$ of inhibition at the concentration of $100 \mu \mathrm{g} / \mathrm{mL}$ while ascorbic acid has $48.63 \%$ at the same concentration which was shown in Fig. 9. AgNPs reduces more DPPH than the ascorbic acid which showed higher anti-oxidant activity than the standard.

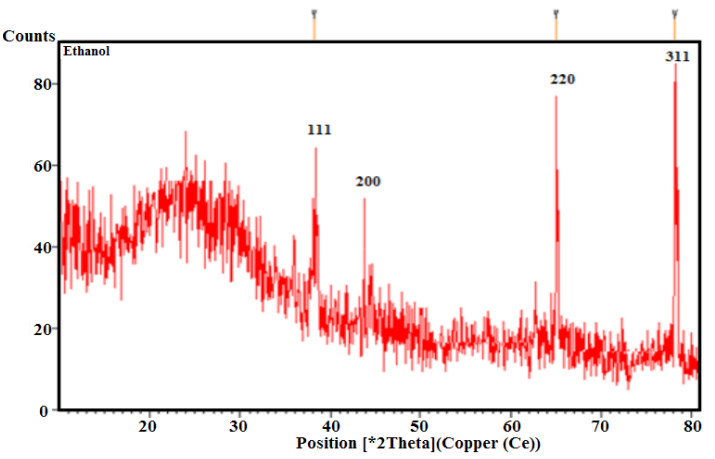

Fig. 8. XRD patterns of silver nanoparticles synthesized using a sample
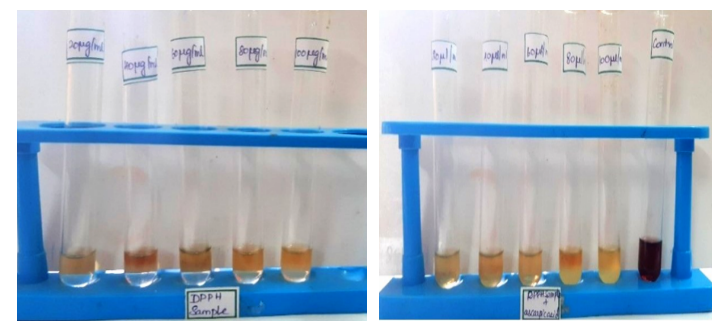

Fig. 9. Antioxidant activity of synthesized silver nanoparticles using $L$. usitatissimum seed by DPPH assay

Table 5: Antioxidant activity of synthesized silver nanoparticles using Linum usitatissimum seed by DPPH assay

\begin{tabular}{|c|c|c|c|}
\hline \multirow[t]{2}{*}{ S. No } & \multirow[t]{2}{*}{ Concentrations } & \multicolumn{2}{|c|}{ Scavenging Effect (\%) } \\
\hline & & Silver Nanoparticles & Ascorbic Acid \\
\hline 1 & $20(\mu \mathrm{g} / \mathrm{mL})$ & $37.81 \pm 0.91$ & $12.78 \pm 0.34$ \\
\hline 2 & $40(\mu \mathrm{g} / \mathrm{mL})$ & $40.57 \pm 0.41$ & $16.56 \pm 0.21$ \\
\hline 3 & $60(\mu \mathrm{g} / \mathrm{mL})$ & $48.13 \pm 0.78$ & $23.08 \pm 0.45$ \\
\hline 4 & $80(\mu \mathrm{g} / \mathrm{mL})$ & $57.23 \pm 0.45$ & $30.12 \pm 0.28$ \\
\hline 5 & $100(\mu \mathrm{g} / \mathrm{mL})$ & $59.01 \pm 0.12$ & $48.63 \pm 0.34$ \\
\hline
\end{tabular}

\section{In vitro alpha-amylase inhibitory assay}

In this study, In vitro alpha-amylase, inhibitory activities of $L$. usitatissimum seed extract were investigated and their results are given in Fig. 10. The results showed that a dose-dependent activity occurs which increases the percentage of inhibitory activity against the alpha-amylase enzyme. The synthesized AgNPs showed the inhibitory 
activity from $61.03 \%$ to $79.84 \%$ at concentrations of 20-100 $\mu \mathrm{g} / \mathrm{mL}$ (Table 6 and Fig. 10). Acarbose is a standard drug for a-amylase inhibitor which showed a-amylase inhibitory activity from 40.12 to $57.01 \%$ at the same concentrations. While comparing the results synthesized AgNPs reveal a greater inhibitory effect than the standard.

Table 6: In vitro alpha-amylase activity of synthesized silver nanoparticles vs standard acarbose

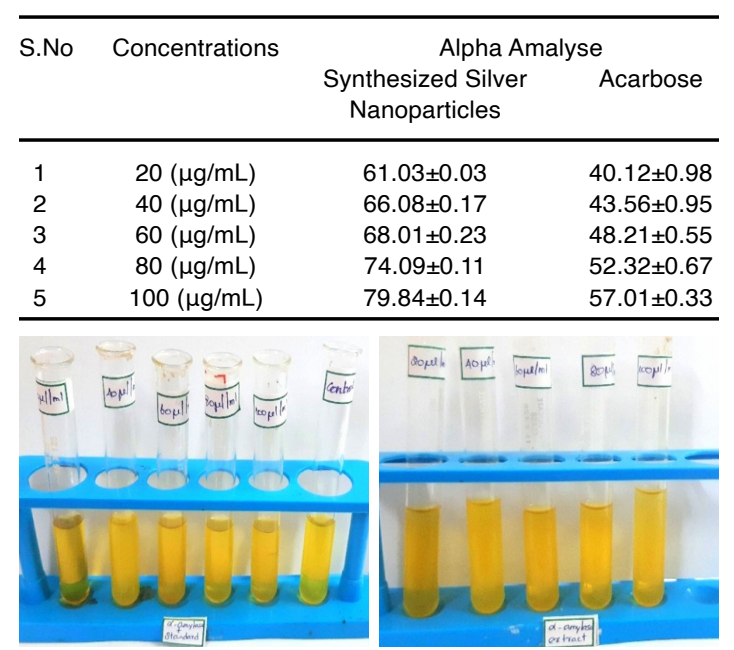

Fig. 10. Antidiabetic activity of synthesized silver nanoparticles using Linum usitalissium plant extracts by an alpha-amylase method

In vitro $\alpha$-glucosidase inhibitory assay

The results of antidiabetic activity using a-glucosidase inhibitory assay of synthesized AgNPs using a Linum usitatissimumseeds extract are shown in Table 7 and Fig. 11. The percentage inhibition at 20-100 $\mu \mathrm{g} / \mathrm{mL}$ concentration of AgNPs showed a dose-dependent activity with the inhibition varied from $43.34 \%$ to $58.86 \%$ from highest concentration to the lowest concentration. While comparing the activity of AgNPs with the acarbose at higher concentration (100 $\mu \mathrm{g} / \mathrm{mL}$ ) AgNPS showed $58.86 \%$ of inhibition but the standard reveals $44.06 \%$ of inhibition against the a- glucosidase inhibitory assay. Thus, the inhibitory of a-glucosidase by AgNPs would delay the degradation of carbohydrates, which causes a decrease in the absorption of glucose, as a result, the reduction of postprandial blood glucose level elevation.
Table 7: In vitro alpha-glucosidase activity of synthesized silver nanoparticles vs standard acarbose

\begin{tabular}{cccr}
\hline S. No & Concentrations & \multicolumn{2}{c}{ Alpha Glucosidase (\%) } \\
& & $\begin{array}{c}\text { Synthesized Silver } \\
\text { Nanoparticles }\end{array}$ & Acarbose \\
& & & \\
\hline 1 & $20(\mu \mathrm{g} / \mathrm{mL})$ & $43.34 \pm 0.45$ & $31.12 \pm 0.44$ \\
2 & $40(\mu \mathrm{g} / \mathrm{mL})$ & $47.78 \pm 0.18$ & $36.34 \pm 0.56$ \\
3 & $60(\mu \mathrm{g} / \mathrm{mL})$ & $49.90 \pm 0.11$ & $38.67 \pm 0.74$ \\
4 & $80(\mu \mathrm{g} / \mathrm{mL})$ & $54.01 \pm 0.45$ & $41.02 \pm 0.09$ \\
5 & $100(\mu \mathrm{g} / \mathrm{mL})$ & $58.86 \pm 0.90$ & $44.06 \pm 0.05$ \\
\hline
\end{tabular}

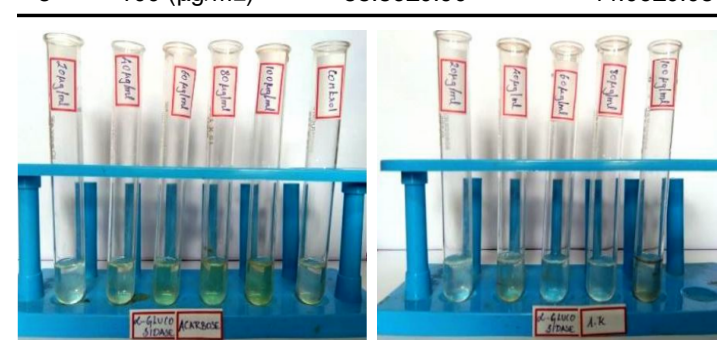

Fig. 11. Antidiabetic activity of synthesized silver nanoparticles using Linum usitalissimium plant extracts by an alpha-glucosidase method

CONCLUSION

In this study, silver nanoparticles were successfully performed by the green method using silver nitrate and $L$. usitatissimum extract used as the reducing agent. The aqueous extract of L. usitatissimum showed the great capability to synthesize the silver nanoparticles. The present study for the first time reports the needle shapes of silver nanoparticles in a greener way. The synthesized nanoparticle has $59 \%$ of elemental silver with noticeable activities of anti-oxidant and anti-diabetic. This study suggests that L. usitatissimum mediated silver nanoparticles can be alternate antioxidants and antidiabetic agents for the treatments which is less toxic and more effective than the existing one.

\section{ACKNOWLEDGEMENT}

The authors thank the Holy Cross College (Autonomous), Trichy for permitting us to do this research work in their laboratory.

\section{Conflicts of interest}

The authors have declared no conflicts of interest.

\section{REFERENCE}

1. Ju-Nam, Y.; Lead, J. R. Manufac nanoparticles: an overview of their chemistry, interactions and potential environmental implications. Sci. Total Environ., 2008, 400 (1-3), 396-414.
2. Sharma, V. K.; Yngard, R. A.; Lin, Y. Silver nanoparticles: green synthesis and their antimicrobial activities. Adv. Colloid Interface Sci., 2009, 145(1-2), 83-96. 
3. Fabrega, J.; Luoma, S. N.; Tyler, C. R.; Galloway, T. S.; Lead, J. R. Silver nanoparticles: behavior and effects in the aquatic environment. Environ. Int., 2011, 37 (2), 517-531.

4. Jagpreet Singh.; Tanushree Dutta.; Ki-Hyun Kim.; Mohit Rawat.; Pallabi Samddar.; Pawan Kumar. Green' synthesis of metals and their oxide nanoparticles: applications for environmental remediation. J. Nanobiotechnology., 2018, 16(84).

5. Perk, A. A.; Shatynska-Mytsyk, l.; Gerçek, Iryna Shatynska-Mytsyk, Yusuf Can Gerçek.; Kadir Boztaş.; Mevzule Yazgan.; Sundas Fayyaz.; Ammad Ahmad Farooqi. Rutin mediated targeting of signaling machinery in cancer cells. Cancer Cell. International., 2014, 14(124).

6. Hanasaki, Y.; Ogawa, S.; Fukui, S. The correlation between active oxygens scavenging and antioxidative effects of flavonoids, Free Radic. Biol. Med., 1994, 16(6), 845-850.

7. Badole, S.L.; Zanwar, A.A.; Bodhankar, S.L. Antihyperglycemic Potential of Secoisolaricinol Diglucoside. Bioactive Food as Dietary Interventions for Diabetes., 2013, 5, 53-57. https:// doi.org/10.1016/B978-0-12-397153-1.00005-6.

8. Camille Goudenhooft.; Alain Bourmaud.; Christophe Baley. Flax (Linum usitatissimum L.) Fibers for Composite Reinforcement: Exploring the Link Between Plant Growth, Cell Walls Development, and Fiber Properties. Frontiers Plant Sci., 2019, 10(411).

9. Ricky W. Fedeniuk.; Costas G. Biliaderis. Composition and Physicochemical Properties of Linseed (Linum usitatissimum L.) Mucilage. J. Agric. Food Chem., 1994, 42(2), 240-247.

10. Rosaline Vimala, J.; Margret Sheela, S.; Dayana Jeyaleela, G.; Irudaya Monisha, S. Biosynthesis of silver nanoparticles by Melia dubia leaf aqueous extract and its antimicrobial activity, World J. Pharm. Res., 2017, 5(3), 973-981.

11. Krishnapriya Madhu Varier.; Mounika Gudeppu.; Arulvasu Chinnasamy.; Sumathi Thangarajan.; Jesudas Balasubramanian.; Yanmei Li.; Babu Gajendran. Nanoparticles: Antimicrobial Applications and Its Prospects, Adv. Nanostructured Mat. Environ. Remedi., 2019, 12, 321-355.

12. Ali, M.S.; Amin, M.R.; Kamal, C.M.; Hossain, M.A. In vitro antioxidant, cytotoxic, thrombolytic activities and phytochemical evaluation of methanol extract of the A. philippense L. leaves. Asian Pac. J. Trop Biomed., 2013, 3(6), 464-469.

13. Dayana Jeyaleela, G.; Rosaline Vimala, J.; Anthony Diwakar chandran, T.; Benno Susai Vijayakumar, A. Preliminary Phytochemical Analysis, Antioxidant activity and Identification of Bioactive Compound in Stem and Leaf of Combretum Ovalifolium, Int. J. Sci. Techno. Res., 2020, 9(3), 3125-3132.

14. Dilaveez Rehana.; Mahendiran, D.; Senthil kumar,R.; Kalilur rahiman, A.In vitro antioxidant and antidiabetic activities of zinc oxide nanoparticles synthesized using different plant extracts. Bioprocess Biosyst Eng., 2017, 40(6), 943-957.

15. Viswanathan Vinotha.; Baskaralingam Vaseeharan.; Viswanathan Vinotha.; ArokiadhasIswarya.; Rajagopalan Thaya.; Marimuthu Govindarajan.; Naiyf S. Alharbi.; ShineKadaikunnan.; Jamal M. Khaled.; Mohammed N. Al-Anbr.; Baskaralingam Vaseeharan. Synthesis of $\mathrm{ZnO}$ nanoparticles using insulin-rich leaf extract: Anti-diabetic, antibiofilm, and anti-oxidant properties. J. Photochem. Photobiol. B., 2019, 197, 111541. 